\title{
Gastroretentive Matrix Tablets of Boswellia Oleogum Resin: Preparation, Optimization, In Vitro Evaluation, and Cytoprotective Effect on Indomethacin-Induced Gastric Ulcer in Rabbits
}

\author{
Rehab Mohammad Yusif, ${ }^{1,3,4}$ Irhan Ibrahim Abu Hashim, ${ }^{1}$ Elham Abdelmonem Mohamed, ${ }^{1}$ and \\ Farid Abd-Elreheim Badria ${ }^{2}$
}

\begin{abstract}
Received 11 February 2015; accepted 4 June 2015; published online 20 June 2015
Abstract. Currently available anti-ulcer drugs suffer from serious side effects which limited their uses and prompted the need to search for a safe and efficient new anti-ulcer agent. Boswellia gum resin (BR) emerged as a safe, efficient, natural, and economic potential cytoprotective agent. Thus, it is of medical importance to develop gastroretentive (GR) formulations of BR to enhance its bioavailability and antiulcer efficacy. Early attempts involved the use of organic solvents and non-applicability to large-scale production. In this study, different tablet formulations were prepared by simple direct compression combining floating and bioadhesion mechanisms employing hydroxypropyl methylcellulose (HPMC), sodium carboxymethyl cellulose (SCMC), pectin (PC), and/or carbopol (CP) as bioadhesive polymers and sodium bicarbonate (SB) as a gas former. The prepared tablets were subjected for assessment of swelling, floating, bioadhesion, and drug release in $0.1 \mathrm{~N} \mathrm{HCl}$. The optimized GR formulation was examined for its protective effect on the gastric ulcer induced by indomethacin in albino rabbits compared with lactose tablets. The obtained results disclosed that swelling, floating, bioadhesion, and drug release of the GR tablets of BR depend mainly on the nature of the matrix and the ratio of polymer combinations. Moreover, a combination of SCMC-CP in a ratio of 2:1 (SCP21) exhibited desirable floating, bioadhesion, swelling, and extended drug release. Also, a 6-h pretreatment with SCP21 tablets decreased the severity of inflammation and number of bleeding spots among ulcer-induced rabbits in comparison to those treated with lactose tablets.
\end{abstract}

KEY WORDS: bioadhesion; Boswellia gum resin; cytoprotective; floating; gastroretentive.

\section{INTRODUCTION}

Despite great advances in drug delivery, the oral drug administration route remains to be the most acceptable due to its economic cost, ease of administration, and patient compliance. However, the oral bioavailability is affected by many factors especially their gastric residence time. The brief gastric emptying time can result in incomplete drug release and diminished efficacy (1). Thus, the retention of oral dosage forms in the upper gastrointestinal tract (GIT) would prolong drug contact

Electronic supplementary material The online version of this article (doi:10.1208/s12249-015-0351-8) contains supplementary material, which is available to authorized users.

${ }^{1}$ Department of Pharmaceutics, Faculty of Pharmacy, Mansoura University, Mansoura, 35516, Egypt.

${ }^{2}$ Department of Pharmacognosy, Faculty of Pharmacy, Mansoura University, Mansoura, 35516, Egypt.

${ }^{3}$ Department of Pharmaceutics and Pharmaceutical Technology, College of Pharmacy, Taibah University, Al-Madinah AlMunawarah, 41411, KSA.

${ }^{4}$ To whom correspondence should be addressed. (e-mail: rehabyusif@yahoo.com) time with the gastrointestinal (GI) mucosa imparting higher bioavailability and efficacy and reduced frequency of administration (2). Since that, the development of a gastroretentive drug delivery system (GRDDS) is sometimes desirable especially for drugs locally acting in the stomach $(3,4)$.

Various approaches have been developed to increase the retention of oral dosage forms in the stomach. Among these are bioadhesion to the gastric mucosa (5), swelling or size expansion to prevent their passage through the pylorus $(6,7)$, high-density systems that settles down in the stomach (8), and floating drug delivery systems (FDDS) that remain buoyant above the gastric fluid (9). FDDS have been classified into two main groups: (1) effervescent formulations that produce carbon dioxide gas in contact with gastric contents and (2) noneffervescent formulations which include microporous systems, alginate beads, hydrodynamically balanced systems, and hallow microsphere-microballoons (10).

Use of one approach to provide an effective GRDD sometimes is not successful as in case of floating system that necessitates sufficient fluid in the stomach for tablet buoyancy. Hence, various combined gastroretentive mechanisms were utilized to overcome this limitation and enhance gastroretention capabilities (11). A swellable floating matrix tablet of ciprofloxacin 
hydrochloride using hydroxypropyl methylcellulose (HPMC), swelling agents (e.g., crospovidone, sodium starch glycolate, and croscarmellose sodium), and sodium bicarbonate (SB) showed more favorable swelling, drug release, and floating characteristics than a marketed product (CIFRAN OD®) (12). As well, a swelling-floating GRDDS of losartan based on a combination of hydroxyethyl cellulose (HEC) and sodium carboxymethyl cellulose (SCMC) offered a greater safety and an improved bioavailability relative to an immediate-release product (Cozaar®) (13).

A large number of drugs have been used for the treatment of gastric ulcers, e.g., antacids, proton pump inhibitors, and antihistaminics. However, most of these drugs suffer from several adverse reactions which may limit their uses (14). This necessitates a rigorous search for safe, economic, and efficient antiulcer agents. Natural products emerge as a reasonable and affordable source to search for compounds which may be used as potential anti-ulcer agents. Badria et al. have investigated the various therapeutic applications of Boswellia including antiinflammatory $(15,16)$, hepaoprotective $(17)$, immunomodulatory (18), and anti-ulcer (19). Boswellic acids are a mixture of tetra- and penta-cyclic triterpens representing 30-34\% of the oleogum resin and were isolated from Boswellia carterii as presented in Fig. 1 (18).

The anti-ulcer activity might be attributed to the increase in the gastric mucosal resistance, local synthesis of cytoprotective prostaglandins, and/or inhibition of the leukotriene synthesis (20). Regarding the anti-ulcer potential, the total mixture of these acids showed a superior effect compared with the pure isolates as previously reported (20).

The main focus of the studies documented in the literature was to evaluate Boswellia oleogum resin (BR) as an excipient. For example, olibanum resin was utilized as a microencapsulating agent for zidovudine (21). In another study, the binding property of BR in tablet formulation was evaluated using aceclofenac as a model drug (22). However, the only

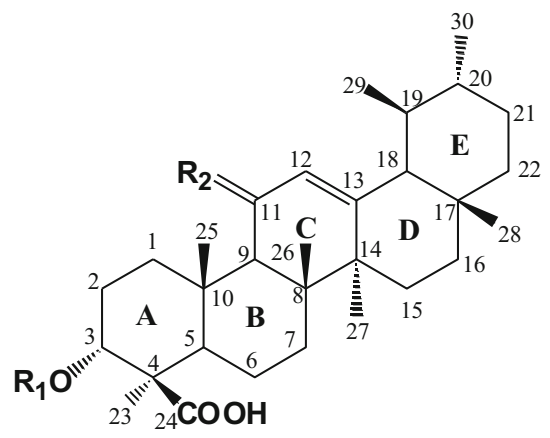
R1 R2
Ac $2 \mathrm{H}$ : acetyl- $\beta$-boswellic acid
Ac O: acetyl-11-keto- $\beta$-boswellic acid (AKBA)
$\mathrm{H} \quad 2 \mathrm{H}$ : $\beta$-boswellic acid
$\mathrm{H} \quad \mathrm{O}$ : 11-keto- $\beta$-boswellic acid

Fig. 1. Chemical structure of major bioactive triterpenoids isolated from the oleogum resin of Boswellia carterii attempt that has been made to prolong the gastric residence time of boswellic acid was reported by Fartyal et al. who formulated boswellic acid as a multiple unit system in the form of floating microspheres (23). In spite of the advantages offered by multiple unit floating dosage forms, they exhibited some limitations as the use of organic solvents and difficulty of large-scale production (24). From a manufacturing standpoint, a single unit dosage form can be prepared using easier techniques compared with the multiple units that demand extrusion spheronization or drug loading onto seed cores during manufacturing limiting the large-scale production (25). Moreover, these multiparticulate systems could release the drug at different sites of the GIT $(26,27)$. On the other hand, single unit dosage forms as monolithic tablets has larger size that could hinder the fast passage via the gastric pylorus (28).

Therefore, this study was designed to formulate gastroretentive matrix (GR) of BR tablets using direct compression technique to improve both cytoprotective activity and prolong the onset of action. The effect of different synthetic and natural bioadhesive polymers on the floating, swelling ability, and in vitro drug release was investigated. Moreover, the in vivo cytoprotective effect of the selected formulation on gastric ulcers induced by indomethacin in rabbits was examined.

\section{MATERIALS AND METHODS}

\section{Materials}

HPMC (K100 LV) and pectin (PC; citrus fruit) were purchased from Fluka, Switzerland and Winlab, a division of Wilfrid Smith, UK, respectively. Carbopol 934P (CP) and magnesium stearate were supplied by Amriya Pharmaceutical Industries Co., Alexandria, Egypt. SCMC, SB, lactose monohydrate, and hydrochloric acid were obtained from El-Nasr Pharmaceutical Chemicals Co., ADWIC, Cairo, Egypt. Indomethacin meglumine was obtained from Chiesi Farmaceutici S.P.A., Parma, Italy. Eosin and hematoxylin were purchased from Merck, Germany. Oleogum resin of B. carterii Birdwood (BR) was purchased from the local herbal stores in Mansoura and authenticated with a genuine sample in the Pharmacognosy Department, Mansoura University, Egypt. All other chemicals were of analytical grade.

\section{Preparation of BR-GR Tablets}

Firstly, BR was dried and grounded into fine powder. The respective powders, namely $\mathrm{BR}, \mathrm{HPMC}, \mathrm{PC}, \mathrm{CP}$, and SCMC as well as a gas-forming agent (SB) were passed through sieve No. 90, separately. Tablets containing $150 \mathrm{mg}$ BR were prepared by direct compression according to the design depicted in Table I. For each formulation, mixing of powders was carried out using a mortar and pestle followed by addition and mixing of lactose monohydrate and magnesium stearate. Finally, $425 \mathrm{mg}$ of each mixture were weighed and fed into the die of a single punch tableting press (Type EKO, ErwekaApparatebau, GmbH, Germany), equipped with flat-faced punches $(10 \mathrm{~mm})$. The compression pressure was adjusted to give tablet hardness a value between 6 and $7 \mathrm{~kg}$. 
Table I. Composition of Boswellia Olegum Resin Gastroretentive (BR-GR) Tablet Formulations

\begin{tabular}{|c|c|c|c|c|c|c|}
\hline Formulae $^{a}$ & Formula code & HPMC & SCMC & $\mathrm{PC}$ & $\mathrm{CP}$ & Lactose \\
\hline HPMC & HPMC & 150 & & & & 60 \\
\hline SCMC & SCMC & & 150 & & & 60 \\
\hline Pectin & $\mathrm{PC}$ & & & 150 & & 60 \\
\hline Carbopol & $\mathrm{CP}$ & & & & 150 & 60 \\
\hline HPMC-carbopol 1:2 & HCP12 & 50 & & & 100 & 60 \\
\hline HPMC-carbopol 1:1 & HCP11 & 75 & & & 75 & 60 \\
\hline HPMC-carbopol 2:1 & HCP21 & 100 & & & 50 & 60 \\
\hline SCMC-carbopol 1:2 & SCP12 & & 50 & & 100 & 60 \\
\hline SCMC-carbopol 1:1 & SCP11 & & 75 & & 75 & 60 \\
\hline SCMC-carbopol 2:1 & SCP21 & & 100 & & 50 & 60 \\
\hline Pectin-carbopol 1:2 & $\mathrm{PCP} 12$ & & & 50 & 100 & 60 \\
\hline Pectin-carbopol 1:1 & PCP11 & & & 75 & 75 & 60 \\
\hline Pectin-carbopol 2:1 & PCP21 & & & 100 & 50 & 60 \\
\hline Control & $\mathrm{C}$ & & & & & 270 \\
\hline Control-1 & $\mathrm{C} 1$ & & & & & 210 \\
\hline
\end{tabular}

$H P M C$ hydroxypropyl methylcellulose, $S C M C$ sodium carboxymethyl cellulose, $P C$ pectin, $C P$ carbopol

${ }^{a}$ All formulae contain $150 \mathrm{mg}$ Boswellia gum resin (BR), and $1 \%$ magnesium stearate. All formulae contain sodium bicarbonate (60 mg) except C

\section{Evaluation of Tablets}

\section{Physical Properties of Tablets}

The hardness, friability percent, and content uniformity of the prepared tablets were determined according to procedures stated in the US pharmacopoeia (29).

\section{In Vitro Bioadhesive Strength Measurement}

Bioadhesive strength of tablets was measured using a modified two-arm balance (30-32). One metal holder was used to suspend the water-collecting beaker to the balance and another to suspend a glass vial to the other side of the balance as shown in Fig. 2. A piece of rabbit stomach mucosa, $3 \times 3 \mathrm{~cm}$, obtained from a local slaughter house and stored in Krebs buffer at $4{ }^{\circ} \mathrm{C}$ upon collection was used as the mucosal membrane. The mucosal membrane was separated by removing the underlying fat and loose tissues. The experiments were performed within $3 \mathrm{~h}$ of procurement of the mucosa. The rabbit gastric mucosa was tied to an inverted $100-\mathrm{mL}$ beaker and placed in a large one $(250 \mathrm{~mL})$. Then, $0.1 \mathrm{~N} \mathrm{HCl}$ was

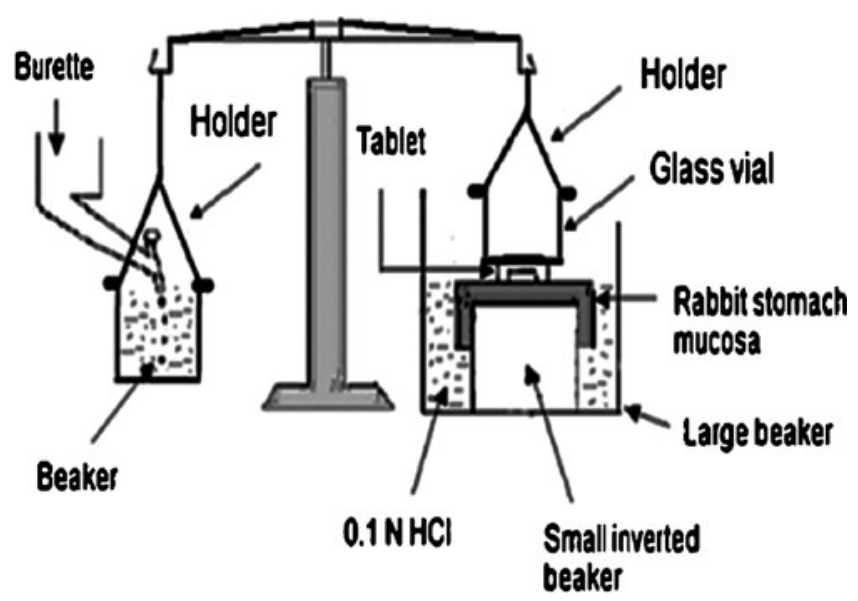

Fig. 2. Bioadhesive strength measurement device added into the large beaker up to the upper surface of the gastric mucosa to maintain mucosal viability during the experiments. Each tablet was attached to the glass vial with adhesive, and then the beaker was raised slowly until contact between rabbit mucosa and the tablet preload time were kept constant for all the formulations. A preload of $50 \mathrm{~g}$ was placed on the vial for $5 \mathrm{~min}$ (preload time) to establish adhesion bonding between tablet and rabbit stomach mucosa. After completion of the preload time, preload was removed from the vial and water was then added into the beaker from the burette in the other side. The addition of water was stopped when the tablet was detached from the rabbit mucosa. The weight of water required to detach the tablet from the mucosa was noted as mucoadhesive strength.

\section{Degree of Tablets Swelling}

The swelling degree of the tablets was determined according to the method previously adopted (33). Briefly, each tablet was individually weighed (W1) and transferred into a beaker containing $200 \mathrm{~mL}$ of $0.1 \mathrm{~N} \mathrm{HCl}$ and maintained in a water bath at $37 \pm 0.5^{\circ} \mathrm{C}$. At regular time intervals, the tablet was removed and the excess surface liquid was carefully removed by a filter paper. The swollen tablet was then reweighed (W2). The mean weights of tablets were determined, and the percent swelling was calculated according to the following equation:

The percent swelling $=\mathrm{W} 2-\mathrm{W} 1 / \mathrm{W} 1 \times 100$

\section{Floating Capacities}

The floating capacities were examined as previously described (34). Glass beakers containing $100 \mathrm{~mL}$ of $0.1 \mathrm{~N} \mathrm{HCl}$ were placed in a water bath shaker at $37 \pm 0.5^{\circ} \mathrm{C}$. The tablets were added separately into these beakers and observed for floating over $24 \mathrm{~h}$. The time required for the tablets to rise to the surface and float (floating lag time, FLT) and the duration of floating (total floating time, TFT) were recorded. 


\section{In Vitro Drug Release}

The drug release from BR-GR tablets was studied using USP apparatus II (Dissolution Apparatus USP Standards, Scientific, DA-6D, Bombay, India). The dissolution test was performed using $900 \mathrm{~mL}$ of $0.1 \mathrm{~N} \mathrm{HCl}$ containing $0.5 \%(w / v)$ sodium lauryl sulfate to provide sink condition $(23,24,33,35-37)$. It was maintained at temperature of $37 \pm 0.5^{\circ} \mathrm{C}$ and stirred at $100 \mathrm{rpm}$. Aliquots $(2 \mathrm{~mL})$ were withdrawn at predetermined time intervals up to $12 \mathrm{~h}$ and replaced by fresh dissolution medium. The samples were diluted, filtered using millipore filter ( $0.45 \mu \mathrm{m}$ pore size and $47 \mathrm{~mm}$ diameter, Gelman GN-6 Metricel membrane filter, USA) and analyzed spectrophotometrically at a wavelength of $239 \mathrm{~nm}$ using an UV/VIS spectrophotometer (V-550, Jasco, Japan). Plots of cumulative amount released $v$ s. time were constructed.

\section{Analysis of Release Data}

To survey more precisely the mechanism of drug release from the investigated formulations, their in vitro release data were analyzed mathematically according to the following models: zero-order kinetics (cumulative \% drug released $v s$. time), first-order kinetics (log \% drug retained $v s$. time), Higuchi model (cumulative \% drug released vs. square root of time) (38), and Korsmeyer-Peppas equation (log amount of drug released vs. log time) (39). The model with the highest coefficient of determination $\left(r^{2}\right)$ was considered as the best fitting one.

\section{In Vivo Evaluation of Optimized Gastroretentive BR Tablets}

\section{Induction of Gastric Erosions and Ulcers into Rabbit Model}

Male New Zealand rabbits, aged 10-11 weeks and weighing 2.1-2.5 kg, were enrolled in this study. The experimental procedures conform to the ethical principles of the scientific committee of the Faculty of Pharmacy, Mansoura University, Egypt for the use of experimental animals.

The animals were deprived of food but allowed free access to water for $24 \mathrm{~h}$ before the day of doing the experiment. The anti-ulcerogenic effect of BR-GR tablets were investigated using indomethacin-induced gastric ulceration. The rabbits were divided into four groups ( $n=6$ per group) as follows: group I, received normal saline (control group); group II, received $20 \mathrm{mg} / \mathrm{kg}$ indomethacin orally (untreated); group III, received BR-lactose tablet $6 \mathrm{~h}$ before oral administration of indomethacin; and group IV, received orally (SCP21 formula) $6 \mathrm{~h}$ before oral administration of indomethacin. One hour after indomethacin administration, rabbits were sacrificed and their stomachs were excised for further macroand microscopical examination.

\section{Morphological Evaluation of Gastric Erosions}

Immediately after rabbit's sacrifice, the freshly excised stomachs were dissected and cut along the greater curvature. The mucosa were rinsed with normal saline to remove blood contaminant, if any, and stretched on a feline board for macroscopical examination. Gross mucosal lesions were recognized as hemorrhage or linear streaks (erosions) with damage to the mucosal surface. Paul's index was used to assess ulcerogenic effect. It is the integral indicator of the number of lesions induced per formula and is calculated by multiplying the mean number of ulcers and $\%$ of rabbits with ulcers and then divided by $100 \%$. Moreover, the anti-ulcer activity (AA) of the preparations was calculated by dividing Paul's index of the untreated group by that of the experimental group. The tested formulation was considered active if AA was at least of two units (40).

\section{Histopathological Examination of Gastric Erosions}

Specimens of stomach of rabbits were fixed in $10 \%$ neutral-buffered formalin for $24 \mathrm{~h}$, dehydrated in ascending grades of alcohol, cleared in xylene, and embedded in paraffin. Paraffin sections were cut at $6 \mu \mathrm{m}$ for hematoxylin and eosin stain (41). They were ranked according to the severity of the inflammatory reaction as follows: severe reaction $(+++)$, moderate reaction $(++)$, mild reaction $(+)$, almost normal tissue $( \pm)$, and tissue totally free from any inflammatory reaction $(-)$.

\section{Statistical Analysis}

The resulting data are represented as mean \pm SD. Statistical analysis of the data was carried out using one-way ANOVA followed by Tukey-Kramer multiple comparisons test at a level of significance of $p<0.05$ with Instat Graphpad prism software (version 4.00; Graphpad software, San Diego, CA, USA).

\section{RESULTS AND DISCUSSION}

\section{Physical Characterization of the Tablets}

All formulations showed drug uniformity ranged from $98.1 \%$ to $103.51 \%$ and percentage friability values less than $1 \%$, indicating good mechanical resistance.

The hardness of the prepared formulations was adjusted at $6-7 \mathrm{~kg}$. At hardness $<6 \mathrm{~kg}$, the friability percent was found to be $>1 \%$. At higher hardness $(>7 \mathrm{~kg})$, the obtained tablets showed relatively longer FLT ( $>5 \mathrm{~min}$ ) that might be attributed to the low porosity that would hinder water penetration and hydration of the outer polymer layer preventing the tablets to float (42).

\section{In Vitro Bioadhesive Strength Measurement}

Bioadhesion is a strategy to overcome the highly variable residence times at various sites in the GIT improving the efficacy. The interaction between chemical groups of the polymeric chain and in particular hydroxyl, carboxyl, amine, esteric, and amide groups of hydrophilic polymers and mucus via $\mathrm{H}$-bonding or van der Waals forces can contribute to good adhesion properties (43). Moreover, polymers swelling ability and the mobility of molecules facilitate the interpenetration and interaction with the mucus layer (44-46).

The bioadhesive strength values of the prepared tablets were influenced by the nature of the bioadhesive polymers and showed the order of $\mathrm{CP}>\mathrm{SCMC}>\mathrm{PC}>\mathrm{HPMC}$ (Table II). 
Table II. Floating Properties and Mucoadhesion of Boswellia Olegum Resin Gastroretentive (BR-GR) Tablet Formulations

\begin{tabular}{lccc}
\hline Formulae & Floating lag time (FLT; s) & Floating duration (TFT; h) & Mucoadhesion $(\mathrm{g})$ \\
\hline HPMC & $36.56 \pm 3.40$ & $>24$ & $21.44 \pm 3.12$ \\
SCMC & $28.11 \pm 2.30$ & $>24$ & $35.12 \pm 2.56$ \\
PC & $31.40 \pm 1.24$ & $>24$ & $31.51 \pm 3.11$ \\
CP & Immediately & $5.5 \pm 0.50$ & $40.50 \pm 4.12$ \\
HCP12 & immediately & $8.5 \pm 0.91$ & $32.50 \pm 3.26$ \\
HCP11 & $<5$ & $>24$ & $31.25 \pm 2.67$ \\
HCP21 & $9.5 \pm 0.06$ & $>24$ & $29.60 \pm 2.03$ \\
SCP12 & Immediately & $7.6 \pm 0.63$ & $39.00 \pm 0.93$ \\
SCP11 & $<5$ & $>24$ & $36.70 \pm 2.78$ \\
SCP21 & $8.3 \pm 0.07$ & $>24$ & $36.40 \pm 1.65$ \\
PCP12 & immediately & $6.3 \pm 0.72$ & $36.75 \pm 2.34$ \\
PCP11 & $<5$ & $>24$ & $32.90 \pm 1.98$ \\
PCP21 & $9.34 \pm 0.04$ & $>24$ & $31.50 \pm 0.98$ \\
\hline
\end{tabular}

Each value represents the mean \pm S.D. $(n=3)$

$H P M C$ hydroxypropyl methylcellulose, $S C M C$ sodium carboxymethyl cellulose, $P C$ pectin, $C P$ carbopol

The lowest bioadhesive strength was observed with HPMC tablets probably due to more neutral cellulose groups and thus fewer hydrogen bonds with glycoprotein mucin leading to weaker adhesive forces (47). On the other hand, SCMC and their carboxylic groups can increase the surface charge density of the tablets and hence, form more hydrogen bonds with tissue. Moreover, SCMC tablets had initial faster hydration rate which promotes interpenetration of the polymer chain with the tissue (48). Also, pectin, as a negatively charged polymer, is known for good mucoadhesion related to a balance between available hydrogen bonding sites and an open expanded conformation (49).

The highest mucoadhesive strength was obtained with CP tablets probably due to the numerous proton-donating carboxylic groups in CP forming hydrogen bonds with the negatively charged mucus gel (50). As well, formation of intermolecular complexes of CP with the glycoprotein could explain its high mucoadhesive strength (51). Nevertheless, the ionized part of $\mathrm{CP}$ has also a bioadhesive force due to the diminished intramolecular hydrogen bonds and a stretched cylindrical shape allowing higher penetration to the mucin network than the coil form of unionized CP (52). The high molecular weight, presence of strong hydrogen bond forming groups (carboxylic acid), anionic nature and sufficient chain flexibility are responsible for the high bioadhesion of CP (53). These factors together may explain the benefit of the combination of $\mathrm{CP}$ with each of HPMC, SCMC, and PC in different ratios. These combinations showed comparatively higher bioadhesion compared with HPMC, SCMC, and PC individually as depicted in Table II. In all these formulations, as the CP concentration increased, the mucoadhesive strength also increased. Similar results were previously obtained (35).

\section{Degree of Tablets Swelling}

Swelling percent describes the amount of water that is contained within the hydrogel at equilibrium and is a function of the network structure, hydrophilicity, and ionization of the functional groups (54). The tablet ability to hydrate influences tablet buoyancy, adhesion of swellable polymers, and drug release kinetics (55).
The obtained results highlighted strong differences among $\mathrm{CP}$, SCMC, PC, and HPMC tablets regarding percent swelling (Fig. 3a). HPMC tablets exhibited less swelling ability than others with a maximum of $109.6 \pm 11.6$ after $7 \mathrm{~h}$ possibly due to the neutral cellulose groups. While, CP, SCMC, and PC are polyelectrolytes that provide hydrogel with electrostatic charges and hence, the repulsion established between similar charges forces the polymer chains to a more elongated state than that found in a neutral network, thus increasing the swelling ability (56).

CP tablets exhibited the highest water uptake and a swelling profile that can be divided into two distinct phases (Fig. 3a). During rapid swelling phase $(0-5 \mathrm{~h})$, the swelling percentage increased till reached the maximum value $(282.15 \pm 17.2)$ after $5 \mathrm{~h}$. The second phase $(5-$ $12 \mathrm{~h}$ ) is characterized by a gradual decrease of the swelling percent till a value of $(225.1 \pm 21.3)$ after $12 \mathrm{~h}$ which might be due to the dissolution of the gel formed around tablets. It was previously reported that, CP is insoluble in gastric fluid (GF) and, its swelling behavior is attributed to the uncharged $-\mathrm{COOH}$ group that get hydrated by forming hydrogen bonds with the imbibing water and, therefore, extending the polymer chain (57). However, the basic gas generating agent, $\mathrm{SB}$, could change $\mathrm{pH}$ of GF in the local environment of the swollen region around the tablet to a neutral or alkaline, increasing the ionization of $\mathrm{CP}$ which generates negative charges along their backbone, and hence, repulsion of similar charges occurred allowing uncoiling of the polymer and an extended structure (58).

SCMC tablets showed a high swelling percentage throughout the first $2 \mathrm{~h}$, indicating rapid hydration and high affinity to the test medium, then reaching a maximum of 260.8 \pm 4.7 within $8 \mathrm{~h}$ followed by a decrease that might be due to the slow and gradual erosion of the polymeric matrix (Fig. 3a). This figure also shows that the maximum swelling percentage $(182.7 \% \pm 8.1)$ of PC tablets was achieved after $7 \mathrm{~h}$ due to gel formation, uncoiling of the structure of PC molecules, and the formation of hydrogen bonds with water molecules (59). The swelling of PC tablets was significantly $(p<0.05)$ lower than SCMC or CP. Then, PC gel erodes, goes into solution, and hence, the swelling percentage decreased. Similar results were previously obtained (60). 

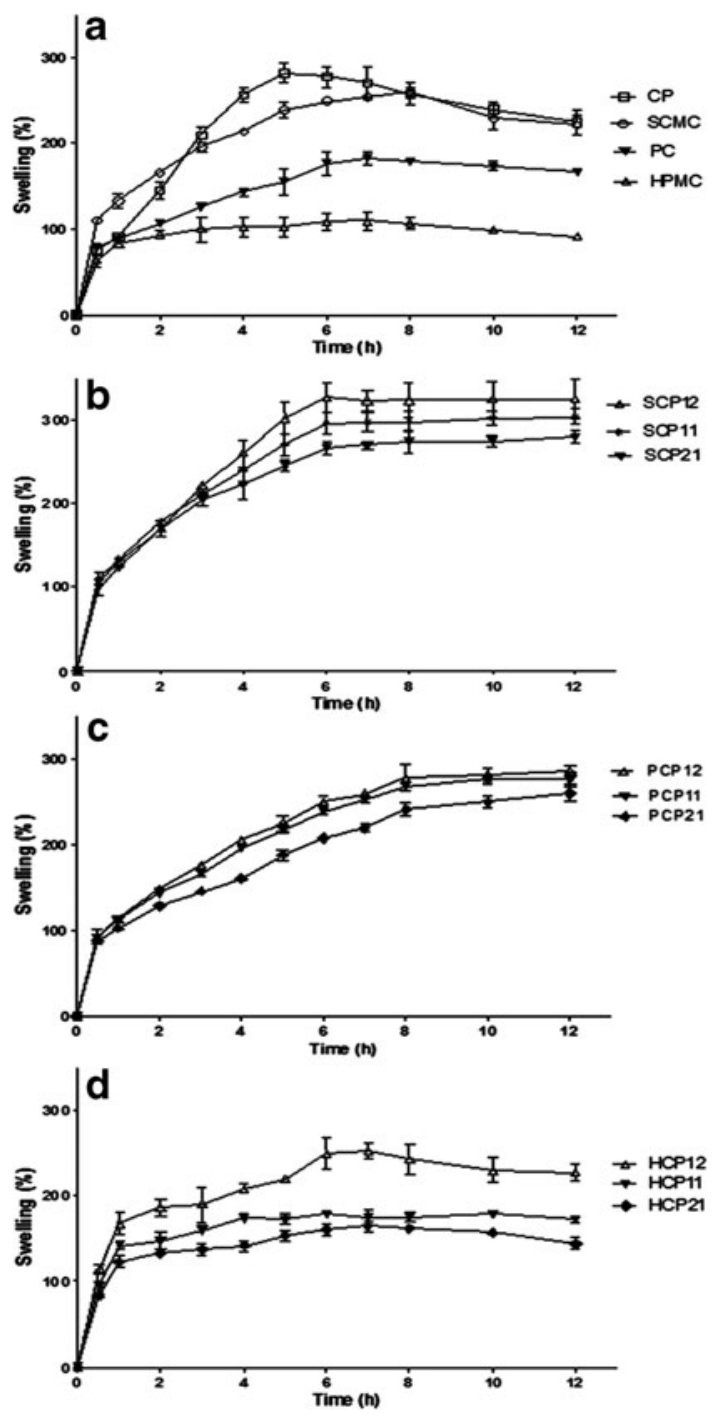

Fig. 3. Swelling profiles of tablets containing individual polymers (a), SCMC-CP combinations (b), PC-CP combinations (c), and HPMC-CP combinations (d). Each point represents the mean $\pm \mathrm{SD}(n=3)$

In view of the above mentioned data, $\mathrm{CP}$ appeared to be a promising base matrix due to its high bioadhesive strength, maximum swelling percentage, and good gelling properties. Therefore, its effect on the extent of swelling was further investigated after mixing with each of HPMC, PC, or SCMC in different ratios.

The swelling profiles of SCP12, SCP11, and SCP21 tablets are shown in Fig. 3b. The higher CP content within the SCMC network increased the percentage of swelling and decreased the time for maximum swelling in comparison with those containing SCMC alone probably due to more carboxylic moieties and more expanded network. Similar behavior was also noticed with PC-CP or HPMC-CP matrices as depicted in Fig. 3c, d. However, the maximum swelling percentage of SCMC-CP formulations was significantly higher $(p<0.05)$ than those of the corresponding PC-CP or HPMC-CP formulations in GF that may be explained by the higher swelling of SCMC compared with PC and HPMC.

\section{Floating Capacities}

To attain in vitro buoyancy, SB was used as an effervescent base during formulation of BR-GR tablets. Upon contact of the formulated tablets with $0.1 \mathrm{~N} \mathrm{HCl}$ as a dissolution medium, the acid-base reaction starts producing $\mathrm{CO}_{2}$ gas which is entrapped in the hydrocolloid gel matrix, and hence, the tablets float (61). The increase in the gas producing agent (60 vs. $30 \mathrm{mg}$ ) significantly shortened FLT, yet, it did not affect TFT. So, SB was added in an amount of $60 \mathrm{mg}$ to all formulated tablets.

The results for FLT and TFT are illustrated in Table II. Immediate floating was observed with $\mathrm{CP}$ tablets upon contact with the release medium, while, the FLT values of SCMC, PC, and HPMC were between 28.11 and $36.56 \mathrm{~s}$. Tablets containing SCMC, PC, or HPMC remained buoyant over the media for periods longer than $24 \mathrm{~h}$ possibly due to the development of a gel matrix with a higher strength to trap the air bubbles and maintain buoyancy for a longer time (24). However, those containing CP alone floated only for $6 \mathrm{~h}$ since $\mathrm{CP}$ has a high tendency to imbibe water as previously observed from the swelling study, thus, the density of this formulation increased considerably after $6 \mathrm{~h}$ upon contact with water inhibiting the prolonged floating $(24,62)$.

Regarding CP combinations with each of HPMC, SCMC, and $\mathrm{PC}$ in different ratios revealed that increasing the amount of $\mathrm{CP}$ in the tablets was concomitant with a decrease in the FLT. Concerning the TFT, all CP combinations floated for periods longer than $24 \mathrm{~h}$ except those containing high ratio of $\mathrm{CP}$ (HCP12, PCP12, and SCP12) that experienced TFT of 8.7, 7.6, and $6.3 \mathrm{~h}$, respectively. As mentioned above, this may be due to the higher tendency of CP to imbibe water and the subsequent increase in density inhibiting the prolonged floating.

\section{In Vitro Drug Release}

Gastroretentive drug delivery systems based on one mechanism may fail to provide an efficient prolonged release of incorporated drugs in the stomach (13). For example, bioadhesive systems encounter a challenge with the high turnover rate of gastric mucus. Similarly, the performance of floating and swelling-expanding drug delivery systems is strongly affected by the filling state of the stomach and, after predetermined time intervals; they break into smaller pieces, leaving the stomach (63). Thus, combining different gastroretentive mechanisms was considered to enhance gastroretention capabilities $(13,64)$.

To obtain a controlled drug delivery of BR to the stomach by combining floating and bioadhesion, several matrix-gel bioadhesive polymers such as CP, HPMC, SCMC, and PC in combination with $\mathrm{SB}$ as a gas former were examined with respect to their effects on the drug release in GF. Lactose was used as a diluent for the formulated tablets, so the drug release from tablets containing lactose without any of these polymers ( $\mathrm{C}$ tablets) was studied. It was found that, the dissolution rate of the drug from $\mathrm{C}$ tablets was slow and requires a period of $8 \mathrm{~h}$ for about $95 \%$ of the drug to be released as shown in Fig. 4a. This may be referred to the poor solubility of $\mathrm{BR}$ in water, particularly in acidic environment due to its acidic nature (65). Also, the effect of the gas former, SB, on $\mathrm{BR}$ release was evaluated. A complete drug release was achieved within $4 \mathrm{~h}$ from $\mathrm{C} 1$ tablets which contains SB and 

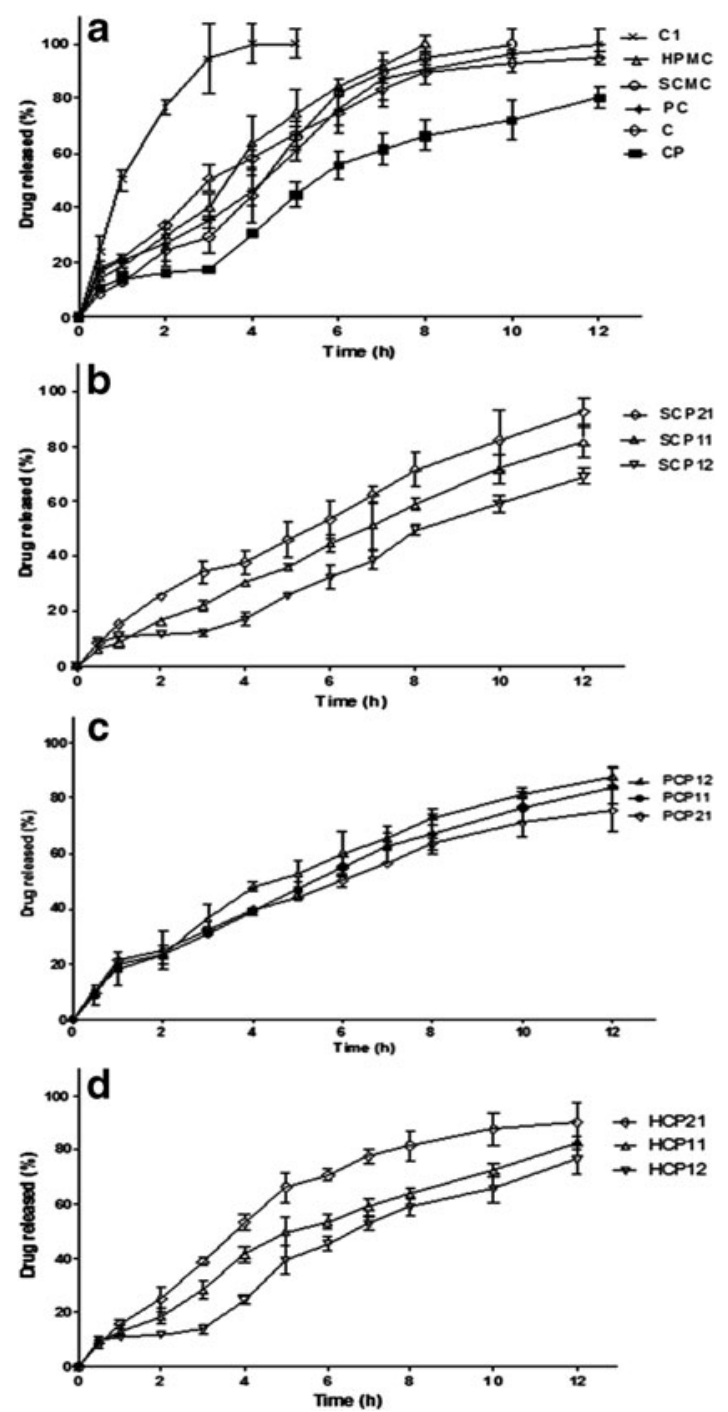

Fig. 4. Release profiles of $\mathrm{BR}$ from tablets containing individual polymers (a), SCMC-CP combinations (b), PC-CP combinations (c), and HPMC-CP combinations (d). Each point represents the mean \pm $\mathrm{SD}(n=3)$ lactose without polymers as shown in Fig. 4a. This behavior could be due to the alkaline microenvironment provided after the dissolution of SB content within the tablet matrix resulting in increased dissolution of the acidic drug.

The apparent drug release rate observed from PC, SCMC, and HPMC tablets, each alone, exhibited a substantial decrease compared with that from C1 tablets (Fig. 4a). Furthermore, their drug release patterns were similar with percent drug released after $8 \mathrm{~h}\left(\mathrm{Q}_{8} \mathrm{~h}\right)$ ranging from 90.63 to 100 . Thus, no considerable differences were observed among the three polymers as they seemed to behave similarly in modulating the drug release rate via formation of a gel layer around the tablets upon contact with dissolution medium followed by erosion of the swellable matrix into smaller particles exposing more surfaces for dissolution and drug release (66).

The incorporation of $\mathrm{CP}$ alone with $\mathrm{SB}$ as a matrix tablet significantly $(p<0.05)$ decreased the drug release rate compared with the other matrix-gel forming tablets, where $\mathrm{Q}_{8} \mathrm{~h}$ was 66.33 (Fig. 4a). This behavior may be explained on the basis that $\mathrm{CP}$ is a cross-linked polymer with high molecular weight and viscosity imparting a thick gel structure upon contact with the dissolution medium. Moreover, the alkaline microenvironment created by the dissolved SB within the tablet matrix could enhance this gelling effect of $\mathrm{CP}$ slowing further penetration of the dissolution medium (67). On the other hand, there is an inverse relationship between drug release rate and tablet dimensions, where, the increase in tablet size by swelling causes a decrease in drug release rate (68). Addition of SB to formulations containing CP was suggested to improve their retarding effect in acidic media by making the matrices form a stronger polymer network (69).

On combining SCMC with CP, the $\mathrm{Q}_{8}$ h were 71.5, 58.5, and 49.6 for SCP21, SCP11, and SCP12, respectively, as depicted in Fig. 4b. Statistical analysis revealed that SCP11 and SCP12 formulations significantly $(p<0.05)$ decreased the drug release compared with those containing SCMC alone. According to the results of the swelling study, both polymers showed high hydrophilicity and water uptake producing a swollen gel-like state that may substantially reduce the penetration of dissolution medium into the tablets and decrease the drug release rate $(70)$.

Table III. Kinetic Modeling of Drug Release Profiles

\begin{tabular}{lcccccc}
\hline & Zero order & First order & Higuchi model & \multicolumn{2}{c}{ Korsmeyer-Peppas } \\
\cline { 2 - 5 } Formula code & \multicolumn{1}{l}{ Correlation coefficient $\left(r^{2}\right)$} & & $r^{2}$ & Diffusional exponent $(n)$ & Drug transport mechanism \\
\hline HPMC & 0.976 & 0.841 & 0.942 & 0.997 & 0.727 & Non-Fickian \\
SCMC & 0.938 & 0.925 & 0.954 & 0.995 & 0.666 & Non-Fickian \\
PC & 0.916 & 0.947 & 0.958 & 0.997 & 0.702 & Non-Fickian \\
CP & 0.948 & 0.952 & 0.870 & 0.964 & 0.656 & Non-Fickian \\
HCP 12 & 0.961 & 0.968 & 0.932 & 0.969 & 0.626 & Non-Fickian \\
HCP 11 & 0.961 & 0.993 & 0.985 & 0.995 & 0.677 & Non-Fickian \\
HCP 21 & 0.901 & 0.990 & 0.959 & 0.998 & 0.698 & Non-Fickian \\
SCP 12 & 0.971 & 0.927 & 0.878 & 0.974 & 0.587 & Non-Fickian \\
SCP 11 & 0.997 & 0.970 & 0.975 & 0.998 & 0.636 & Non-Fickian \\
SCP 21 & 0.991 & 0.951 & 0.965 & 0.999 & 0.619 & Non-Fickian \\
PCP 12 & 0.958 & 0.990 & 0.989 & 0.998 & 0.693 & Non-Fickian \\
PCP 11 & 0.981 & 0.985 & 0.976 & 0.996 & 0.671 & Non-Fickian \\
PCP 21 & 0.980 & 0.986 & 0.979 & 0.995 & 0.667 & Non-Fickian \\
\hline
\end{tabular}


Compared with tablets containing $\mathrm{PC}$ alone, the drug release was slower when $\mathrm{PC}$ was mixed with $\mathrm{CP}$ at different ratios, 1:1, 1:2, and 2:1 (Fig. 4c). Yet, increasing the $\mathrm{CP}$ content in PC-CP tablets did not significantly modify the drug release rate. In other words, the degree of retardation of drug release from GR tablets was independent of the PC-CP ratio. The obtained data may suggest that the hydration of these tablets is followed by the completion of a stable gel layer resulting in no difference in release rate from the delivery system.

The release profiles of BR from tablets containing HPMCCP mixtures are illustrated in Fig. 4d. HCP21, HCP11, and HCP12 formulations containing HPMC-CP in respective ratios of $2: 1,1: 1$, and $1: 2$, have $Q_{8}$ h values of $81.45 \%, 63.79 \%$, and $58.75 \%$, respectively. During dissolution test, it was observed that erosion of HCP21 tablets occurred resulting in higher percent of drug released. Further increase in the amount of CP in HPMC-CP mixtures (HCP11 and HCP12) maintained the integrity of the tablets and imparted a significant $(p<0.05)$ decrease in the drug release in comparison with HPMC alone or HCP21. As a result, the tablets remained intact over a period of $12 \mathrm{~h}$ probably due to the high swelling nature of CP. Similar findings were previously reported $(24,62)$. Other investigators reported that the possible $\mathrm{H}$-bonding between $\mathrm{OH}$ group of HPMC and carboxyl group of CP may lead to stronger crosslinking between the two polymers and formation of a thick gel structure which would retard the drug release $(71,72)$.

SCP21 formulation was selected as the optimized one since it met the required criteria to form gel instantaneously in the $\mathrm{pH}$ conditions of the stomach and was able to keep its integrity. It showed excellent floating and swelling characteristics. Furthermore, it exhibited a promising initial drug release followed by a controlled behavior for a desired period of time. This initial faster hydration rate may promote the interpenetration of the tablet matrix within the gastric mucosa. Based on these findings, SCP21 was chosen for in vivo evaluation.

\section{Drug Release Kinetics}

The values of $r^{2}$ obtained from different kinetics models in Table III suggest that the drug release from the formulations may follow any one of these models. Korsmeyer and Peppas equation superposes two apparently independent mechanisms of drug transport, Fickian diffusion and a case-II transport, for the description of drug release from a swelling polymer (39). For a matrix tablet, when $n$ equals the value of 0.45 , it indicates diffusion-controlled drug release. In case of $n$ equals 0.89 , it indicates swelling-controlled drug release. Values of $n$ between 0.45 and 0.89 can be regarded as an indicator for both the
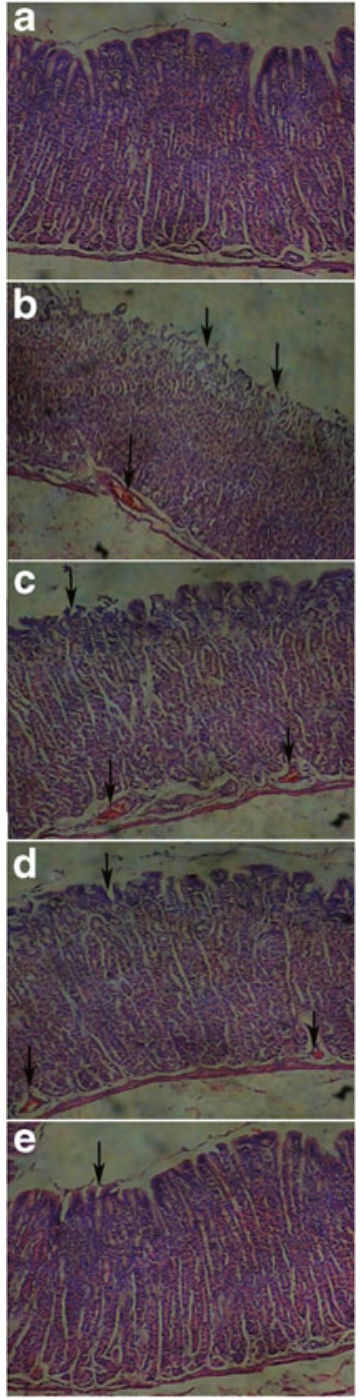

Fig. 5. Histological examination of stomach of rabbits in group I (control) showing normal structure features (a), in group II showing erosion (b) or destruction (c) of the lining epithelium and congested blood vessels in submucosal layer (indicated by arrows), in group III showing erosion of the lining epithelium and congested blood vessels in the submucosal layer (indicated by arrows; d), and in group IV showing only minor erosion of epithelial layer with non-congested blood vessels (e)

phenomena (anomalous transport). As shown in Table III, it is clear that all formulae have $n$ values between 0.587 and 0.727 , indicating anomalous transport and a drug release controlled by a coupling of diffusion and erosion.

Table IV. Paul's Index, Anti-ulcer Activity, and Severity of Inflammatory Reaction of Different Rabbits Groups

\begin{tabular}{lccccc}
\hline \multicolumn{1}{c}{ Treatment (group) } & $\begin{array}{c}\text { Number of ulcers } \\
(\text { mean } \pm \text { SD; } n=6)\end{array}$ & $\begin{array}{c}\text { \% incidence } \\
\text { of rabbits }\end{array}$ & $\begin{array}{c}\text { Paul's } \\
\text { index }\end{array}$ & $\begin{array}{c}\text { Anti-ulcer activity } \\
\text { (\%AA) }\end{array}$ & $\begin{array}{c}\text { Severity of inflammatory } \\
\text { reaction }\end{array}$ \\
\hline I (control; no drug) & Zero & Zero & Zero & - & - \\
II (indomethacin; $20 \mathrm{mg} / \mathrm{kg}$ ) & $13.16 \pm 0.84$ & 100 & 13.16 & - & ++ \\
III (control; BR-lactose) & $9.20 \pm 0.40^{*}$ & 83.33 & 11.04 & 1.21 & ++ \\
IV (GR formula; SCP 21) & $1.66 \pm 0.34^{*}+$ & 50 & 3.32 & 3.59 & \pm \\
\hline
\end{tabular}

$* p<0.05 v s$. indomethacin; ${ }^{\dagger} p<0.05 v s$. control (BR-lactose) tablets 


\section{Macroscopical Examination of Rabbits Stomach}

Stomach of group I (control) showed neither inflammation nor hemorrhage. However, the mucosa of stomach in group II which received indomethacin orally showed marked red patches of erosions. This finding was manifested by the presence of high number of ulcers, high \% incidence of rabbits with ulcers $(100 \%)$, and hence, the highest Paul's index, 13.16 (Table IV). When BR-lactose formula was given $6 \mathrm{~h}$ before indomethacin administration (group III), high number of ulcers with high Paul's index were found. However, the administration of BR-GR formula (SCP21), $6 \mathrm{~h}$ before indomethacin administration (group IV), showed significantly smaller numbers of ulcers or erosions $(p<0.05)$ in comparison with group II (untreated) or group III (received BR-lactose tablets). Furthermore, a smaller value of Paul's index was obtained with group IV in comparison with group II and group III (3.32 vs. 13.16 and 11.04), respectively. They also displayed a satisfactory anti-ulcer activity $(\mathrm{AA}>2)$. It is to be pointed out that, the AA of BR was prolonged for $6 \mathrm{~h}$ only when it was administered as GR tablets $(\mathrm{AA}=3.59)$.

\section{Histopathological Investigation of Rabbits Stomach}

Stomach of the control group showed normal structure features of the mucosa which lined by intact surface columnar epithelium (Fig. 5a). After administration of indomethacin to group II, the gastric mucosa exhibited a destruction (Fig. 5b) or erosion (Fig. 5c) of the lining epithelium with congested blood vessels in the submucosal layer. These results indicated damaged cells of gastric mucosa after administration of indomethacin. Indomethacin showed a higher ulcerogenic potential than other non-steroidal anti-inflammatory drugs (NSAIDs) possibly via inhibiting the release of protective factors; e.g. cyclooxygenase-1 (COX-1), prostaglandin E2 (PEG2), bicarbonate, mucus, and anti-oxidant parameters as well as stimulating aggressive factors; e.g. acid, and oxidant parameters (73).

On the other hand, the tissue of the stomach of rabbits receiving control lactose tablets (group III) $6 \mathrm{~h}$ before indomethacin administration showed moderate reaction where erosion of the mucous layer and congestion of the blood vessels were detected in the submucosal layer (Fig. 5d). Meanwhile, the severity of reaction in group IV was within the normal limit as the submucosal layer does not show congested blood vessels, where only minor ulceration in the lining epithelium was noticed as presented in Fig. 5e. Regarding the severity of inflammatory reaction in the rabbit's stomach, the different rabbit's groups could be arranged in a descending order as follows: group II (no treatment) $>$ group III $>$ group VI $>$ group I (control group) (Table IV). Thus, formulation of BR into GR tablets prolonged its residence in the stomach and increased its solubility due to SB content leading to higher bioavailability with prominent prolonged gastroprotective effect. So, maintenance of a local concentration of $\mathrm{BR}$ for a longer time in the rabbit stomach could increase the gastric mucosal resistance and local synthesis of cytoprotective prostaglandins, thus, protect the rabbits from occurrence of ulcer more effectively than its control formula. The greater gastric cytoprotective effect of GR floating tablets of pantoprazole and nizatidine than their conventional dosage forms has been confirmed $(74,75)$.

\section{CONCLUSION}

Using simple compression, different GR tablets of the natural safe anti-ulcer BR were formulated. Among these, tablets containing combination of SCMC-CP in ratios of 2:1(SCP21) showed satisfactory results with respect to FLT, TFT, swelling, bioadhesion, and extended drug release up to $12 \mathrm{~h}$. The in vivo study proved the superiority of SCP21 formula over control BR-lactose tablets due to its prolonged cytoprotective effect against gastric ulceration induced by indomethacin.

\section{REFERENCES}

1. Rouge N, Buio P, Doelker E. Drug absorption sites in the gastrointestinal tract and dosage forms for site-specific delivery. Int $\mathrm{J}$ Pharm. 1996;136:117-39.

2. Fell JT. Targeting of drugs and delivery systems to specific sites in the gastrointestinal tract. J Anat. 1996;189:517-9.

3. Murphy CS, Pillay V, Choonara YE, Du Toit LC. Gastroretentive drug delivery systems: current developments in novel system design and evaluation. Curr Drug Deliv. 2009;6:451-60.

4. Nayak AK, Maji R, Das B. Gastroretentive drug delivery systems: a review. Asian J Pharm Clin Res. 2010;3:2-10.

5. Bravo-Osuna I, Vauthier C, Farabollini A, Palmieri GF, Ponchel G. Mucoadhesion mechanism of chitosan and thiolated chitosanpoly(isobutyl cyanoacrylate) core-shell nanoparticles. Biomaterials. 2007;28:2233-43.

6. El-Zahaby SA, Kassem AA, El-Kamel AH. Formulation and in vitro evaluation of size expanding gastro-retentive systems of levofloxacin hemihydrates. Int J Pharm. 2014;464:10-8.

7. Sugihara H, Matsui Y, Takeuchi H, Wilding I, Connor A, Abe K, et al. Development of a gastric retentive system as a sustained release formulation of pranlukast hydrate and its subsequent in vivo verification in human studies. Eur J Pharm Sci. 2014;53:62-8.

8. Tuleu C, Andrieux C, Boy P, Chaumeil JC. Gastrointestinal transit of pellets in rats: effect of size and density. Int $\mathrm{J}$ Pharm. 1999;180:123-31.

9. Stops F, Fell JT, Collett JH, Martini LG. Floating dosage forms to prolong gastro-retention-the characterisation of calcium alginate beads. Int J Pharm. 2008;350:301-11.

10. Garg R, Gupta GD. Progress in controlled gastroretentive delivery systems. Trop J Pharm Res. 2008;7:1055-66.

11. Chitnis VS, Malshe VS, Lalla JK. Bioadhesive polymers-synthesis, evaluation and application in controlled release tablets. Drug Dev Ind Pharm. 1991;17:879-92.

12. Arza RAK, Gonugunta CSR, Veerareddy PR. Formulation and evaluation of swellable and floating gastroretentive ciprofloxacin hydrochloride tablets. AAPS PharmSciTech. 2009;10:220-6.

13. Chen RN, Ho HO, Yu CY, Sheu MT. Development of swelling/ floating gastroretentive drug delivery system based on a combination of hydroxyethyl cellulose and sodium carboxymethyl cellulose for Losartan and its clinical relevance in healthy volunteers with CYP2C9 polymorphism. Eur J Pharm Sci. 2010;39:82-9.

14. Bruntan LL, Lazo JS, Parker KL. Goodman and Gilman's: the pharmacological basis of therapeutics. 11th ed. New York: McGraw Hill Companies; 2006.

15. Badria FA, El-Farahaty T, Shabana AA, Hawas SA, El-Batoty MF. Boswellia-curcumin preparation for treating knee osteoarthritis: a clinical evaluation. Alt Complement Ther. 2002;8:341-8.

16. Badria FA, Mohammed E, El-Badrawy M, El-Desouky M. Natural leukotriene inhibitor from Boswellia: a potential new alternative for treating bronchial asthma. Alt Complement Ther. 2004;10:257-65.

17. Badria FA, Houssen WE, El-Nashar EM, Saaed SA. Effect of glycyrrhizin and Boswellia carterii extract on liver injury: biochemical and histopathological evaluation. Biosci Biotech Res Asia. 2003;1:93-6.

18. Badria FA, Mikhaeil BR, Maatooq GT, Amer MMA. Immunomodulatory triterpenoids from the oleogum resin of Boswellia carterii Birdwood. Z Naturforsch C. 2003;58:505-16. 
19. Badria FA. Preparation a new product of natural origin for treatment of hyperacidity and colitis. Egyptian Patent \# 23376. 2001 (April 30, 2001 expires April 29, 2021, Egypt).

20. Singh S, Khajuria A, Taneja SC, Khajuria RK, Singh J, Johri RK, et al. The gastric ulcer protective effect of boswellic acids, a leukotriene inhibitor from Boswellia serrata, in rats. Phytomedicine. 2008;15:408-15.

21. Panda S, Pattnaik S, Maharana L, Botta GB, Mohapatra P. Formulation and evaluation of zidovudine loaded olibanum resin microcapsules: exploring the use of natural resins as biodegradable polymeric materials for controlled release. Asian J Pharm Clin Res. 2013;6:191-6.

22. Chaudhari SP, Patil PR, Deshmukh TA, Tekade BW, Patil VR. Evaluation of binding properties of Boswellia serrata Roxb. gum in tablet Formulation. J Pharm Educ Res. 2011;2:61-5.

23. Fartyal S, Jha SK, Karchuli MS, Gupta R, Vajpayee A. Formulation and evaluation of floating microspheres of Boswellic acid. Int J Pharm Tech Res. 2011;3:76-81.

24. Tavakoli N, Varshosaz J, Dorkoosh F, Motaghi S, Tamaddon L. Development and evaluation of a monolithic floating drug delivery system for acyclovir. Chem Pharm Bull. 2012;60:172-7.

25. Mcconnell EI, Basit AW. Modified release oral drug delivery. In Aulton ME, Taylor KMG, editors. Aulton's pharmaceutics the design and manufacture of medicines. Fourth edition; 2013. p. 555.

26. Srinatha A, Pandit JK. Multi-unit floating alginate system: effect of additives on ciprofloxacin release. Drug Deliv. 2008;15:471-6.

27. Sahoo SK, Mohapatra S, Dhal SK, Behera BC, Barik BB. Formulation of floating microspheres of ciprofloxacin hydrochloride by crosslinking technique. Ind Pharm. 2007;6:65-8.

28. Davis SS, Stockwell AF, Taylor MJ, Hardy JG, Whalley DR, Wilson CG, et al. The effect of density on the gastric emptying of single-and multiple-unit dosage forms. Pharm Res. 1986;3:208-13.

29. USP28-NF23. "The United States Pharmacopeia" 28th, The National Formulary 23rd: The United States Pharmacopoeial Convention, Inc., Washington, 2005.

30. Desai KGH, Kumar TMP. Preparation and evaluation of a noval buccal adhesive system. AAPS PharmSciTech. 2004;5:1-9.

31. Singh S, Jain S, Muthu MS, Tiwari S, Tilak R. Preparation and evaluation of buccal bioadhesive films containing clotrimazole. AAPS PharmSciTech. 2008;9:660-7.

32. Singh S, Soni R, Rawat MK, Jain A, Deshpande SB, Singh SK, et al. In vitro and in vivo evaluation of buccal bioadhesive films containing salbutamol sulphate. Chem Pharm Bull. 2010;58:307-11.

33. Tadros MI. Controlled-release effervescent floating matrix tablets of ciprofloxacin hydrochloride: development, optimization and in vitro-in vivo evaluation in healthy human volunteers. Eur J Pharm Biopharm. 2010;74:332-9.

34. Jaimini M, Rana AC, Tanwar YS. Formulation and evaluation of famotidine floating tablets. Curr Drug Deliv. 2007;4:51-5.

35. Darandale SS, Vavian PR. Design of a gastroretentive mucoadhesive dosage form of furosemide for controlled release. APSB. 2012;2:509-17.

36. Chun MK, Bhusal P, Choi HK. Application of carbopol/PVP interpolymer complex to prepare mucoadhesive floating granule. Arch Pharm Res. 2013;36:745-51.

37. USP31-NF26. "The United States Pharmacopeia" 31st, The National Formulary 26th: The United States Pharmacopoeial Convention, Inc., Washington, 2008, pp. 1303-1306.

38. Higuchi T. Mechanism of sustained action medication. J Pharm Sci. 1963;52:1145-9.

39. Korsmeyer RW, Gurny R, Docler E, Buri P, Peppas NA. Mechanism of solute release from porous hydrophilic polymers. Int J Pharm. 1983:15:25-35.

40. Zueva EP, Reikhart DV, Krylova SG. 2003. Medicinal plants in therapy of gastroduodenal ulcer. In Krylova SG, Khotimchenko YS, Zueva EP, Amosova EN, Razina TG, Efimova LA. Gastroprotective effect of natural non-starch polysaccharides. Bull Exp Biol Med. 2006; 142:454-7.

41. Bancroft JD, Gamble M. Theory and practice of histological techniques. 5th ed. London: Churchill Livingstone; 2002. p. 130.

42. Hasçiçek C, Yüksel-Tilkan G, Türkmen B, Özdemir N. Effect of formulation parameters on the drug release and floating properties of gastric floating two-layer tablets with acetylsalicylic acid. Acta Pharm. 2011;61:303-12.
43. Bigucci F, Luppi B, Cerchiara T, Sorrenti M, Bettinetti G, Rodriguez L, et al. Chitosan/pectin polyelectrolyte complexes: selection of suitable preparative conditions for colon-specific delivery of vancomycin. Eur J Pharm Sci. 2008;35:435-41.

44. Duchene D, Touchard F, Peppas NA. Pharmaceutical and medical aspects of bioadhesive systems for drug administration. Drug Dev Ind Pharm. 1988;14:283-318.

45. Gurny R, Meyer JM, Peppas NA. Bioadhesive intraoral release systems: design, testing and analysis. Biomaterials. 1984;5:336-40.

46. Peppas NA, Buri PA. Surface, interfacial and molecular aspects of polymer bioadhesion on soft tissues. J Control Rel. 1985;2:257-75.

47. Choi MK, Jung JH, Ryu JM, Yoon SJ, Oh YK, Kim CK. Development of in-situ gelling and mucoadhesive acetaminophen liquid suppository. Int J Pharm. 1998;165:33-44.

48. Peh KK, Wong CF. Polymeric films as vehicle for buccal delivery: swelling, mechanical, and bioadhesive properties. J Pharm Pharm Sci. 1999;2:53-61.

49. Madsen F, Eberth K, Smart JD. A rheological examination of the mucoadhesive/mucus interaction: the effect of mucoadhesive type and concentration. J Control Release. 1998;50:167-78.

50. Gu JM, Robinson JR, Leung SHS. Binding of acrylic polymers to mucin/epithelial surface: structure property relationships. Crit Rev Ther Drug Carrier Syst. 1988;5:21-67.

51. Mortazavi SA, Smart JD. Factors influencing gel strengthening at the mucoadhesive mucus interface. J Pharm Pharmacol. 1994;46:86-90.

52. Hassan EE, Gallo JM. Simple rheological method for the in vitro assessment of mucin polymer bioadhesive bond strength. Pharm Res. 1990;7:491-5.

53. Singla AK, Chawla M, Singh A. Potential applications of carbomer in oral mucoadhesive controlled drug delivery system: a review. Drug Dev Ind Pharm. 2000;26:913-24.

54. Nanjwade BK, Adichwal SA, Nanjwade VK, Gaikwad KR, Thakare SA, Manvi FV. Development and evaluation of gastroretentive floating tablets of glipizide based on effervescent technology. J Drug MetabToxicol. 2012;3:1-6.

55. Mitchell K, Ford JL, Armstrong DJ, Elliott PNC, Rostron C, Hogan JE. The influence of concentration on the release of drugs from gels and matrices containing Methocel®. Int J Pharm. 1993;100:155-63.

56. Sannino A, Demitri C, Madaghiele M. Biodegradable cellulosebased hydrogels: design and applications. Materials. 2009;2:353-73.

57. Mortazavi S. In vitro assessment of mucus/mucoadhesive interactions. Int J Pharm. 1995;124:173-82.

58. Praveen G. Development and in vitro evaluation of buccoadhesive tablets of losartan potassium. Pharma Innov. 2012;1:63-70.

59. Kaur A, Kaur G. Mucoadhesive buccal patches based on interpolymer complexes of chitosan-pectin for delivery of carvedilol. SPJ. 2012;20:21-7.

60. Talukdar MM, Kinget R. Swelling and drug release behavior of xanthan gum matrix tablets. Int J Pharm. 1995;120:63-72.

61. Goole J, Deleuze P, Vanderbist F, Amighi K. New levodopa sustained-release floating minitablets coated with insoluble acrylic polymer. Eur J Pharm Biopharm. 2008;68:310-8.

62. Li S, Lin S, Daggy BP, Mirchandani HL, Chien YW. Effect of HPMC and carbopol on the release and floating properties of gastric floating drug delivery system using factorial design. Int $\mathrm{J}$ Pharm. 2003;253:13-22.

63. Streubel A, Siepmann J, Bodmeier R. Drug delivery to the upper small intestine window using gastroretentive technologies. Curr Opin Pharmacol. 2006;6:501-8.

64. Nur AO, Zhang JS. Captopril floating and/or bioadhesive tablets: design and release kinetics. Drug Dev Ind Pharm. 2000;26:965-9.

65. Karlina M, Pozharitskaya O, Kosman V, Ivanova S. Molecularbiological problems of drug design and mechanism of drug action, bioavailability of boswellic acids: in vitro/in vivo correlation. Pharm Chem J. 2007;41:569-72.

66. Omidian H, Park K. Swelling agents and devices in oral drug delivery. J Drug Delivery Sci Technol. 2008;18:83-93.

67. Kar R, Mohapatraa S, Bhanjaa S, Das D, Barik B. Formulation and in vitro characterization of xanthan gum-based sustained release matrix tablets of isosorbide-5-mononitrate. Iran J Pharm Res. 2010;9:13-9. 
68. Salve P. Development and in vitro evaluation of gas generating floating tablets of metformin hydrochloride. Asian J Res Pharm Sci. 2011;1:105-12.

69. Bravo SA, Lamas MC, Salomon CJ. Swellable matrices for the controlled-release of diclofenac sodium: formulation and in vitro studies. Pharm Dev Technol. 2004;9:75-83.

70. Emami J, Varshosaz J, Saljoughian N. Development and evaluation of controlled-release buccoadhesive verapamil hydrochloride tablets. DARU. 2008;16:60-9.

71. Kumar R, Patil MB, Patil SR, Paschapur MS. Formulation and evaluation of effervescent floating tablet of famotidine. Int $\mathrm{J}$ Pharm Tech Res. 2009;1:754-63.
72. Samani SM, Montaseri H, Kazemi A. The effect of polymer blends on release profiles of diclofenac sodium from matrices. Eur J Pharm Biopharm. 2003;55:351-5.

73. Suleyman H, Albayrak A, Bilici M, Cadirci E, Halici Z. Different mechanisms in formation and prevention of indomethacininduced gastric ulcers. Inflammation. 2010;33:224-34.

74. Balata G. Design and evaluation of gastroretentive floating tablet of nizatidine: a trial to improve its efficacy. Int J Pharm Pharm Sci. 2014;6:423-9.

75. Sarangapani S, Bangaru J, Rajappan M. In vitro and in vivo evaluation of the gastroretentive floating dosage form. Int Res J Pharm. 2014;5:695-700. 